\title{
Exploring the Face-to-Face: Revisiting Patient- Doctor Relationships in a Time of Expanding Telemedicine
}

\author{
Jennifer Y. C. Edgoose, $M D, M P H$
}

\begin{abstract}
The patient-doctor relationship lies at the heart of medicine. Confronted with the challenges of COVID-19, we find ourselves unable to provide care and comfort in the same physical space as our patients. As we are forced to reckon with telemedicine visits and contemplate continuing them in a postpandemic future, it is important to understand the difference relationally between telemedicine and face-to-face encounters. I will argue that face-to-face visits remain essential in establishing the most fundamentally human components of relationships: responsibility and vulnerability. This established bond assures fidelity in subsequent encounters, whether by phone, video, or in person. ( $\mathrm{J}$ Am Board Fam Med 2021;34:S252-S254.)
\end{abstract}

Keywords: COVID-19, Pandemics, Physician-Patient Relations, Telemedicine

In the midst of the coronavirus 2019 pandemic, many of us clinicians have found ourselves sheltering in our homes, trying to practice our craft through the laptop or phone screen. As a family physician, I have always felt that face-to-face interactions are at the heart of who I am and what I do. Yet as severe acute respiratory syndrome coronavirus- 2 is likely to be with us for the unforeseeable future, how can we still foster connection, empathy and a sense of belonging with our patients when our interactions with them take place through telemedicine?

Telemedicine encompasses the "use of technologies and telecommunication systems to administer health care to patients who are geographically separated from providers." 1 Although often used interchangeably with telemedicine, telehealth is a broader term that also includes the application of telecommunication to other aspects of health care such as education, research, and evaluation. ${ }^{1}$

This article was externally peer reviewed.

Submitted 28 July 2020; revised 27 September 2020; accepted 28 September 2020.

From the Department of Family Medicine and Community Health, University of Wisconsin; and University of Wisconsin School of Medicine and Public Health.

Funding: N/A.

Conflict of interest: None declared.

Corresponding author: Jennifer Y. C. Edgoose, MD, MPH, Department of Family Medicine and Community Health, University of Wisconsin School of Medicine and Public Health, 100 Delaplaine Ct., Madison, WI 53715-1896 (E-mail: Jennifer.edgoose@fammed.wisc.edu).
Whereas many organizations have sought definitions of telemedicine and telehealth, curiously faceto-face encounters are defined only in the Affordable Care Act as a requirement for certification of eligibility for Medicare home health services. $^{2}$ Although perhaps obvious that a face-to-face encounter requires a clinician and a patient to be in the same shared space, without exploring the essential aspects of face-to-face interactions, we cannot fully understand what is lost and what is to be gained in moving to a virtual encounter.

It was returning to an afternoon of face-to-face patient care that helped clarify for me why my telemedicine visits were proving to be just as rewarding. Most of the patients I saw that afternoon were like old friends:

- Frank told my staff he'd rather see me in person than have a telemedicine visit. I knew it was a year since ovarian cancer had claimed the life of Frank's wife, also a dear patient of mine, so despite the awkward masks and face shield, we still marked this event with a few tears.

- Shawn updated me on her almost-preteen girls, whom I also care for, and we reflected on how our public-school district might reopen this autumn because she is herself a teacher.

- Laura is now a capable 16-year-old with a litany of adolescent issues but thriving in her work at a community center preparing meals for the foodinsecure and driving a car she purchased herself. 
Although I hadn't seen her for years, I was amazed that she remembered me listening and advocating for her and sharing that I had a daughter who was autistic just like her.

As I reflected on those 3 face-to-face visits, I realized why telemedicine visits have been similarly productive and rewarding this past month: It is because everyone I was calling by phone or video was someone whom I had already met face to face.

Many of us in virtual administrative or academic meetings will often end by saying, "I look forward to when we can meet in person." We are deeply aware on some fundamental level that a phone or video link is not the same, even for people with whom we have a less contractual relationship than that of patientdoctor. As clinicians, we generally first meet patients in an examination or hospital room with the very intentional goal of addressing health and wellness concerns, but despite these formal, sanitized settings, we make eye contact and respond to the specific person-the other-with whom we are face to face. We are able and obliged to respond because no one else is in our shoes, and thus, no one else can respond for us. We healers inherently recognize that this responsibility does not end when we leave the room: "Once we have caught the patient's eye ... we are now in proximity with them [and] our lives are now linked." So it is no surprise that our telemedicine visits with patients whom we already have been bound to by proximity are not merely automated visits of subjective complaints and review of systems but may start as, "I know you called about some numbness in your hand, which we'll address, but how are you doing during these extraordinary times?" And it would not be uncommon for the reply to be, "... .Doctor, thanks for asking but, how are you?"

Once responsibility for the other has been established, we can engage in deeply meaningful virtual visits thereafter because we are now bound to the other; we can conjure up that shared space of intimacy. As the daughter of poor immigrants, it is easy to see poignant examples of how responsibility and connectedness is maintained across vast global distances, even before our 21 st century technological advancements. I also want to point out that this sense of responsibility for the other does not require an hour of dialogue or years of conversation but can happen in a moment. It is that look of someone who seems to look back in astonishment that they actually have been seen or heard for who they are, beyond their body or words. And once this bond is forged, we can now meet by phone or video, knowing and trusting the fidelity of the relationship, knowing it is not just a chronic pain patient on the phone but Kim, whose lumbar magnetic resonance imaging looks as horrendous as her mother's magnetic resonance imaging, for whom you and she both care. And, similarly for Kim, it is not a doctor on the phone but "my doctor."

And what about video telemedicine visits? I remain unconvinced that this is a substitute for a true face-toface encounter. I think that what remains missing is shared context. How we move and negotiate a shared space can seem generous and accommodating or cold and uninviting. It is not to say there are not real benefits to a video visit over a phone visit in assessing the general appearance and demonstration of a rash or a joint's range of movement. One could perhaps get a glimpse of a home and meet other household members or even a beloved pet. But an essential ingredient in what makes true face-to-face encounters most poignant and intriguing is a component of vulnerability by both parties involved and the allure of the unexpected. The small frame of a video remains a constructed vantage from the angle of the camera to the lighting to what the patient allows you to see. What is lost in a video telemedicine visit is the cocreated shared space in which we join with a patient and become something more than our discrete selves.

This may, in fact, demonstrate a unique advantage of the telemedicine visit. The imbalance of power between patient and clinician is important to recognize. Because there is less vulnerability in the separation of space of telemedicine encounters, one may find it easier to engage a patient who already feels vulnerable, perhaps because of past trauma, including trauma experienced in the health care system. We relieve that patient of the burden of responsibility toward their clinician and can start a relationship in this more formulaic and, literally, detached interaction. In fact, this explains why telemedicine visits with patients who are new to us often take so much longer because we still feel a need to win over this patient across space and will assert our wiles and charm, although hampered by the pixelated screen, feeling that something is missing in these encounters. And if the opportunity arises, we hope that this patient may venture into our clinic more confidently the next time.

These are important considerations as we take on new clinical learners who are desperate to learn the art of doctoring and may find themselves on the end of a telemedicine visit with a patient whom they have never met. Whereas we can hope they can have a 
technically proficient visit with the patient, they will miss something essential that comes with sitting behind a closed door with a stranger. We can help them by encouraging them to take a thorough psychosocial history. We can encourage them to look into the eyes of a person on the screen, although in fact they should really be gazing into the light of the camera to look truly directly at the person on the other side. Fundamentally, it remains a manufactured space bereft of the sizing up that happens with firsttime encounters, the shared moment when responsibility is borne and vulnerability exposed.

So whereas technology helps us breach the isolation of quarantine, we must hold onto the ways in which we attain the deeply empathic relationships so needed in these precarious times. Bereft of props and adjustments, we face a patient in a room, both vulnerable to the other, each unsure where the interaction will lead. Thereafter as we respond in the face of that infinite uncertainty, we take on a deep and unspoken responsibility for the patient that cannot ever be escaped. And it is this that serves as the basis for all our interactions with that patient to come, whether by phone, video, or in person.

My sincere thanks to Julian Edgoose, $\mathrm{PhD}$, whose expertise in Levinasian philosophy helped me clearly articulate these thoughts and whose close proximity was an anchor for me during these precarious times.

To see this article online, please go to: http://jabfm.org/content/ 34/Supplement/S252.full.

\section{References}

1. NEJM Catalyst. What is telehealth? NEJM Catalyst 2018;4:1. https://catalyst.nejm.org/doi/full/.

2. Department of Health and Human Services Center for Medicare and Medicaid Services. Medicare home health face-to-face requirement. https:/www.cms.gov/Medicare/ Medicare-Fee-for-Service-Payment/HomeHealthPPS/ downloads/face-to-face-requirement-powerpoint. pdf.

3. Edgoose JYC, Edgoose JM. Finding hope in the face-to-face. Ann Fam Med 2017;15:272-4.2. 